\title{
A PSICODINÂMICA DO TRABALHO: NOÇÕES TEÓRICAS E PRÁTICAS
}

\section{Cyndi Naymayer Peres ${ }^{1}$; Alberto Francisco Carvalho Mallmann²; Amanda Marchi do Amaral ${ }^{3}$; Liana Bohrer Berni ${ }^{4}$}

\section{RESUMO}

A teoria da psicodinâmica do trabalho apresenta um maior entendimento sobre o adoecimento e a saúde dos trabalhadores. O objetivo deste estudo é relacionar os conceitos da teoria Dejouriana com a realidade prática experienciada por alunos do curso de Psicologia. Utilizou-se para a produção dessa pesquisa uma experiência teórica-prática alicerçando-a aos escritos de Christophe Dejours. Os resultados evidenciaram que o ambiente laboral gera um vasto impacto na saúde dos trabalhadores por causa das particularidades demandadas desse meio. Por fim, é possível através da entrevista identificar a teoria de Dejours e a partir disso, rever e repensar a prática tendo em vista a promoção e prevenção da saúde do trabalhador no ambiente de trabalho.

Palavras-chave: Trabalhadores; Psicopatologia; Escola Dejouriana; Saúde Mental.

Eixo Temático: Atenção Integral e Promoção à Saúde (AIPS)

\section{INTRODUÇÃO}

A psicodinâmica do trabalho é uma abordagem que visa entender como os trabalhadores alcançam certo nível de equilíbrio psíquico e como o mantém, compreendendo também as influências das condições de trabalho na saúde destes indivíduos (MERLO, 2002; DEJOURS, 2011a). Para Dejours (2011a) as pressões sentidas pelos trabalhadores decorrem da organização do trabalho, relacionadas com as questões físicas, químicas, mecânicas e biológicas vivenciadas no ambiente laboral, que podem ocasionar desgastes e doenças, tanto físicas quanto psíquicas.

Esta teoria traz ainda diversos conceitos e contribuições importantes para compreender o adoecimento no ambiente de trabalho assim como o contexto em

\footnotetext{
${ }^{1}$ Acadêmica do curso de Psicologia - UFN. c.peres@ufn.edu.br

${ }^{2}$ Acadêmico do curso de Psicologia - UFN. mallmann.alberto@ufn.edu.br

${ }^{3}$ Acadêmica do curso de Psicologia - UFN. amanda.marchi@ufn.edu.br

${ }^{4}$ Orientadora. Professora do curso de Psicologia - UFN. liana.berni@ufn.edu.br
} 
que ocorrem. Diante disso, este estudo tem como principal objetivo fazer um relato de experiência de um trabalho prático realizado na disciplina de Psicologia e Saúde do Trabalhador. Isto se faz importante visto que amplia a compreensão frente ao conteúdo, mediante a escuta das vivências da realidade social para além da teoria, dessa forma contribuindo para a formação profissional dos pesquisadores da área.

\section{METODOLOGIA}

Este estudo se trata de um relato de experiência de caráter descritivo-analítico, produzido a partir de conhecimentos obtidos na disciplina de Psicologia e Saúde do Trabalhador do curso de Psicologia da Universidade Franciscana (UFN), ao qual envolveu os princípios da teoria psicodinâmica e pode-se assim, aplicá-los e compreendê-los através de uma atividade prática. Primeiramente, estudou-se em sala de aula os conceitos e como avaliação se produziu uma entrevista informal. Esta modalidade é considerada por Gil (2008) por ser simples e de flexível estruturação, no qual seu foco é o levantamento de informações visando obter um entendimento mais amplo da questão em pauta.

Contudo, optou-se por descrever acerca da compreensão obtida desta experiência para não expor os relatos do entrevistado. Logo, este tipo de atividade tem grande importância ao passo que acrescenta no entendimento da prática. Portanto, enfatizando essa experiência, seus pontos de maior importância são relacionados com materiais teóricos e publicações sobre um dos principais temas da psicologia organizacional, em livros e outras produções já elaboradas. Este gênero de estudo esclarece preceitos e amplia os conhecimentos dos fatos investigados através da análise dos conteúdos (GIL, 2008). As informações bibliográficas, em sua grande maioria, foram considerações produzidas por Christophe Dejours, conhecido como o pai da Psicodinâmica do Trabalho.

\section{RESULTADOS E DISCUSSÕES}


Quando inserido em um ambiente de trabalho, o indivíduo é atravessado por diversas questões inerentes ao contexto, como normas, regras, demandas, pressões sociais, políticas, econômicas, psíquicas, entre outras. Para Dejours (2011a) todas essas variáveis são potencialmente desestabilizadoras para a saúde do trabalhador, podendo levar ao adoecimento deste indivíduo, que possui capacidade de defender-se e de reagir a essas variáveis. A psicodinâmica contribui para o entendimento destas vivências individuais de cada profissional ao passo que relaciona prazer e sofrimento que emergem da relação trabalho e trabalhador (MERLO, 2002).

A partir da experiência dos autores na disciplina citada, são pontos de grande relevância na atuação do trabalhador aspectos relacionados à organização do trabalho, como a vasta demanda, poucos profissionais e má distribuição de tarefas, estas quais, são segundo Dejours (2011a), um dos grandes fatores para a desestabilização da saúde mental dos trabalhadores. Por consequência estes aspectos influenciam no interesse pelo trabalho e nas relações afetivas do trabalhador (DEJOURS, 2011a) logo, relacionando à experiência prática, compreendeu-se o quanto questões como a organização das tarefas e o aparecimento de intrigas e ganâncias geram grande estresse e podem assim, conforme Dejours (2011a), afetar o funcionamento psíquico do sujeito.

Como dito anteriormente, cada trabalhador experimenta suas vivências no trabalho de forma única, entretanto utilizam-se de estratégias e recursos que tangem o coletivo e que são conceituadas pela teoria psicodinâmica. Dentre estas estratégias, pode-se destacar a defesa de proteção, descrita por Dejours (2011a) como a manifestação da forma como cada indivíduo pensa, sente e comporta-se. Fundamentado nesse conceito, o sujeito busca sua maneira de enfrentar seu sofrimento ou até mesmo alienar as causas deste, o que ficou amplamente notório com a atividade prática investigada.

Dejours expõe acerca do trabalho prescrito e do real em seus escritos pensando nas vivências dos trabalhadores. $O$ trabalho prescrito refere-se ao que 
cada empresa vai organizar e definir os seus procedimentos, a lógica por trás do sistema de trabalho, as relações entre os departamentos da mesma, suas hierarquias, toda a parte burocrática deste trabalho e como o trabalhador se coloca antes de experienciar a vivência do trabalho (DEJOURS, 2011a; CONSELHO NACIONAL DE JUSTIÇA, 2015). Para além da teoria, entende-se que na realidade o ambiente de trabalho nem sempre dispõe das melhores condições e que lamentavelmente é um processo árduo conquistar melhorias para tornar o ambiente adequado e satisfatório para as demandas do meio.

No que tange ao trabalho real, refere-se àquele que é realizado diariamente pelos colaboradores, que por vezes, diverge do que é aprendido na teoria, pois a natureza do mesmo se apresenta muito mais complexa, dado que não está expressa e prevista em nenhum lugar, ela se apresenta a cada situação e está relacionada ao sentimento vivenciado por esses sujeitos, sendo então aquilo que é feito e não aquilo que foi prescrito em algum lugar anteriormente (DEJOURS, 2004). Dessa forma, percebe-se que os problemas reais diários destoa do trabalhado que é prescrito, dado que por vezes o âmbito não se faz hábil e novas necessidades constantemente surgem.

Quanto ao reconhecimento no trabalho, evidenciou-se que é muito relativo ao sistema da empresa, ao cargo exercido e à questão salarial, o que demonstra que talvez não haja tanta relevância a quantia e qualidade de trabalho. Ao encontro disto, Dejours (2011b) expressa que o reconhecimento vai além do monetário, sendo necessário haver a realização do "eu" pela sociedade, sendo o reconhecimento de terceiros fundamental para isto. Este reconhecimento que os outros conferem traz o sentido deste trabalho, sem isso, seu sofrimento por exercer tal função seria potencializado, perdendo o sentido para esse indivíduo (DEJOURS, 2011b).

Quanto a abertura para diálogo, pode divergir conforme a empresa. Do entendimento que obteve-se através da experiência prática na disciplina do curso, os espaços oportunizados de expressão possibilitam aos funcionários a busca por melhorias. Compreende-se que pela gama de pedidos em grandes empresas, 
poucos acabam sendo levados em consideração e sendo efetivados. Pode-se observar que a resolução dos fatos informados nestes ambientes podem acabar acontecendo de uma forma lenta, mesmo que a solução venha a ser algo muito simples e sem uma grande onerosidade.

No que diz respeito à saúde, verifica-se que o interesse em manter bem-estar se faz presente, no entanto, em razão do expediente de trabalho que se dá de forma corrida, acaba tornando-se difícil estabelecer uma rotina satisfatória que agregue os lazeres que promovam saúde. Com isso, parte do trabalhador procurar meios de preservar-se mesmo com as exigências de sua vida, tanto laboral quanto social.

Por fim, essa noções apontadas nos estudos de Dejours e experienciadas no mundo dos trabalhadores, ou seja, relativo à organização do trabalho, a saúde, a comunicação, a diferenciação do trabalho real e do prescrito, do reconhecimento pelas atividades e das estratégias utilizadas, geram graves impactos no bem-estar dos profissionais. Logo, entende-se que as condições de trabalho implicam em uma gama de exigências e esforços tanto psicológicos quanto físicos tomados na vida dos sujeitos.

\section{CONCLUSÃO}

Diante disso, pode-se concluir com o presente estudo que a teoria da psicodinâmica expressa por Dejours aponta conceitos importantes, que podem ser facilmente identificados na prática laboral dos trabalhadores. Foi possível observar investigando a realidade, a rotina de trabalho, os mecanismos defensivos, a relação com o reconhecimento e com o contexto laboral em geral. Portanto, acredita-se que as vivências consideradas são queixas comuns da realidade social.

Sendo assim, a realização desse estudo foi relevante para o entendimento de como esta teoria se aplica nas vivências dos indivíduos. Consequentemente foram produzidas contribuições significativas para a aprendizagem, sendo esta relevante para a futura formação e atuação como profissionais da psicologia. Considera-se que esse espaço de pesquisa possui ainda poucas informações e pode ser muito 


\section{QUFN}

mais explorado em pesquisas posteriores com uma amostra maior de profissionais. Há muitas necessidades ainda a serem ponderadas, esclarecidas e estudadas pelos organizadores empresariais em função da segurança e saúde dos trabalhadores.

\section{REFERÊNCIAS}

CONSELHO NACIONAL DE JUSTIÇA. Trabalhar na magistratura, construção da subjetividade, saúde e desenvolvimento profissional. Brasil, 2015.

DEJOURS, Christophe. Da Psicopatologia à Psicodinâmica do Trabalho. Rio de Janeiro: Fiocruz \& Paralelo 15, 2004.

DEJOURS, Christophe; ABDOUCHELI, Elisabeth. Itinerário Teórico em Psicopatologia do Trabalho. In: DEJOURS, Christophe; ABDOUCHELI, Elisabeth; JAYET, Christian. Psicodinâmica do trabalho: contribuições da Escola Dejouriana à análise da relação prazer, sofrimento e trabalho. 1. ed. São Paulo: Atlas, 2011a. p. 119-145.

DEJOURS, Christophe; GERNET, Isabelle. Avaliação do trabalho e reconhecimento In: BENDASSOLLI, Pedro, F.; SOBOLL, Lis, Andrea. Clínicas do Trabalho. São Paulo: Atlas, 2011b.

GIL, A. C. Métodos e técnicas de pesquisa social. 6. ed. São Paulo: Atlas, 2008.

MERLO, Álvaro Roberto Crespo. Psicodinâmica do trabalho. In: JACQUES, Maria da Graça; CODO, Wanderley (org.). Saúde mental \& trabalho: leituras. Petrópolis: Vozes, 2002. p. 130-142. 